\title{
Challenges in addressing the knowledge gap on endomyocardial fibrosis through community-based studies
}

\author{
Jenisse Mbanze ${ }^{1}$, Basilio Cumbane ${ }^{1}$, Rolando Jive ${ }^{1}$, Ana Mocumbi ${ }^{2,3}$ \\ ${ }^{1}$ Mozambique Institute for Health Education and Research, Maputo, Mozambique; ${ }^{2}$ Instituto Nacional de Saúde, Maputo, Mozambique; \\ ${ }^{3}$ Universidade Eduardo Mondlane, Maputo, Mozambique \\ Contributions: (I) Conception and design: A Mocumbi; (II) Administrative support: R Jive; (III) Provision of study materials or patients: A Mocumbi; \\ (IV) Collection and assembly of data: J Mbanze, B Cumbane, R Jive; (V) Data analysis and interpretation: All authors; (VI) Manuscript writing: All \\ authors; (VII) Final approval of manuscript: All authors. \\ Correspondence to: Ana Mocumbi, MD, PhD. Instituto Nacional de Saúde, Vila de Marracuene, Estrada Nacional Nº1, Parcela Nº3943, Província de \\ Maputo, Moçambique. Email: amocumbi@gmail.com.
}

\begin{abstract}
Endomyocardial fibrosis (EMF) is a poverty-related disease of unknown origin that afflicts predominantly young people of certain rural areas in low-income countries and can be used to expose global disparities in cardiovascular research. Despite affecting predominantly young people and causing high morbidity and mortality, efforts to understand its mechanisms and natural history have been hampered by the incapacity to detect the early stages of the disease in endemic areas. Dietary, environmental and infectious factors seem to combine in susceptible individuals to give rise to an inflammatory process that leads to endomyocardial damage and scar formation. Lack of awareness by health professionals and low access to health care determine late diagnosis, when complications such as chronic heart failure, thromboembolism and arrhythmia are already present. Open-heart surgery to detach the endocardial fibrous tissue and repair the atrioventricular valve, remains the last resource to prolong patients' survival. Community-based research is therefore needed to understand the epidemiology of EMF, detect early disease, uncover its pathogenesis and explore new therapeutic targets. Our research has shown that echocardiographic screening using standard criteria adds sensitivity and precision to the diagnosis, particularly in asymptomatic disease, providing an opportunity for longitudinal community-based research. However, researchers face major constraints in rural settings where EMF is endemic, including socioeconomic, cultural, geographical and administrative barriers. In presenting our experience we aim to describe the challenges and discuss the lessons learned while implementing community-based research in a highly endemic area in southern Mozambique, one of the poorest countries in the world. Additionally, we discuss how recent advances in medicine-such as use of point-of-care diagnostics, heart failure biomarkers and new imaging techniques-may open new possibilities for high quality research through collaborative partnerships and regional initiatives.
\end{abstract}

Keywords: Community-based research; endomyocardial fibrosis studies

Submitted Jun 25, 2019. Accepted for publication Aug 13, 2019.

doi: $10.21037 / \mathrm{cdt} .2019 .08 .07$

View this article at: http://dx.doi.org/10.21037/cdt.2019.08.07

\section{Introduction}

Global disparities in cardiovascular research are marked and hamper the assessment of Africa's growth trajectory and performance towards sustainable development. Despite globalization, point-of-care devices and internet accessibility there is still a major gap in health data between developed and developing countries $(1,2)$ and a particularly huge deficit of accurate and well-defined health data for policy-making and care provision planning, particularly from the developing countries of Sub-Saharan Africa (SSA).

Cardiovascular disease profile is unique in SSA, 
particularly in poor and rural areas where specific problems in obtaining health information are found, namely due to low access to health services, lack of systematic registration, and absence of continuous data collection on the health situation (3-5). The epidemiology of poverty-related conditions such as rheumatic heart disease and tropical cardiomyopathies is only partially described, despite these conditions being important drivers of service demand. However, cardiovascular diseases are under-represented in the health surveillance systems, and for instance in Mozambique only aggregated data on hospital mortality are collected. Moreover, in this country about $70 \%$ of the population live in rural areas (6), deprived from basic health services $(7,8)$, and a considerable proportion lives below the poverty line. Finally, the health system covers only $40 \%$ of the population and suffers from scarcity of staff and diagnostics, thus affecting health information availability and accuracy. In this context, community-based research is important to provide baseline information to monitor progress towards the achievement of the sustainable development goals (SDG) (9) and cardiovascular disease surveillance is mandatory for prioritization of health education and services planning.

A study that demonstrated a high attack rate of endomyocardial fibrosis (EMF) for people coming to a referral health facility in a rural district in Mozambique (10), triggered a series of community-based research projects that helped to raise the profile of this mysterious and forgotten disease. The implementation of these studies has been a major source of information and constituted a learning experience for those involved. In this review we describe this population-based research, discuss the challenges faced in implementing such studies, and explore the opportunities created by collaborative projects directed to neglected diseases.

\section{EMF: a neglected disease}

Tropical EMF is a poverty-related disease of unknown origin that afflicts predominantly young people of certain rural areas in some low-income countries. EMF is the most common restrictive cardiomyopathy worldwide $(11,12)$ characterized by deposition of fibrous tissue in the endomyocardium, leading to progressive heart failure and death if left untreated. Dietary, environmental and infectious factors seem to combine in susceptible individuals to give rise to an inflammatory process that leads to endomyocardial damage and scar formation that leads to ventricular retraction and atrioventricular valve dysfunction, and predisposes to mural thrombosis, arrhythmia, thromboembolism and chronic cardiac failure (13-15) (Figure 1).

To date no single factor can explain the occurrence of EMF worldwide. While environmental factors are clearly involved as suggested by the finding of the disease in foreign people after short stays in endemic area (16) there also appears to be considerable familial recurrence (17-19). In the absence of knowledge on the exact triggers and mechanisms of disease, most research has been descriptive, and treatment is symptomatic. This is clearly shown by the relatively small number of EMF publications on PubMed-considering its high morbidity and poor outcomes-since its description in 1948 (20). Table 1 shows EMF studies published on PubMed in the last 5 years using the word "endomyocardial fibrosis" and excluding case reports and articles that do not refer to the characteristic tropical EMF accessed on $1^{\text {st }}$ June 2019 (21-27).

Despite data suggesting the reduction in incidence of EMF in some parts of the world, several studies in recent years have shown that EMF is an important cause of service demand in Africa $(28,29)$ and recent publications on the profile of EMF in African patients submitted to echocardiography corroborate this. A retrospective review of echocardiographic reports for studies performed between January 2012 and December 2013 at Uganda Heart Institute evaluated all primary left-sided valve disease and revealed endomyocardial diagnosis in $22(1.7 \%)$ of the 3,582 patients (30). EMF patients had moderate to severe mitral valve regurgitation due to involvement of the mitral valve in left ventricular or biventricular EMF; patients were aged $13-39$ years and $72 \%$ were females (30). Khalil and colleagues in Sudan described EMF in $23(0.5 \%)$ patients ( $52 \%$ females; age 24 to 67 years) out of 4,332 cases studied in four different hospitals in Khartoum, Sudan, recommending a high index of suspicion as all patients presented in functional class III-IV with advanced heart failure (23). In Cote d'Ivoire a retrospective study on 2,612 patients subjected to open heart surgery between 1978 and 2013, 126 had EMF (mean age 12; balanced between right sided form 39, left sided form 40, and bilateral form 47) (31). In a referral hospital in Yaounde, Cameroon of the 1,430 children who had a cardiac anomaly detected on echocardiographic investigation and recorded on their medical files between January 2006 to December 2013, 46 (3.2\%) had EMF (median 10 years; no sex predominance) (32). In a shorter study (5 months) in the 


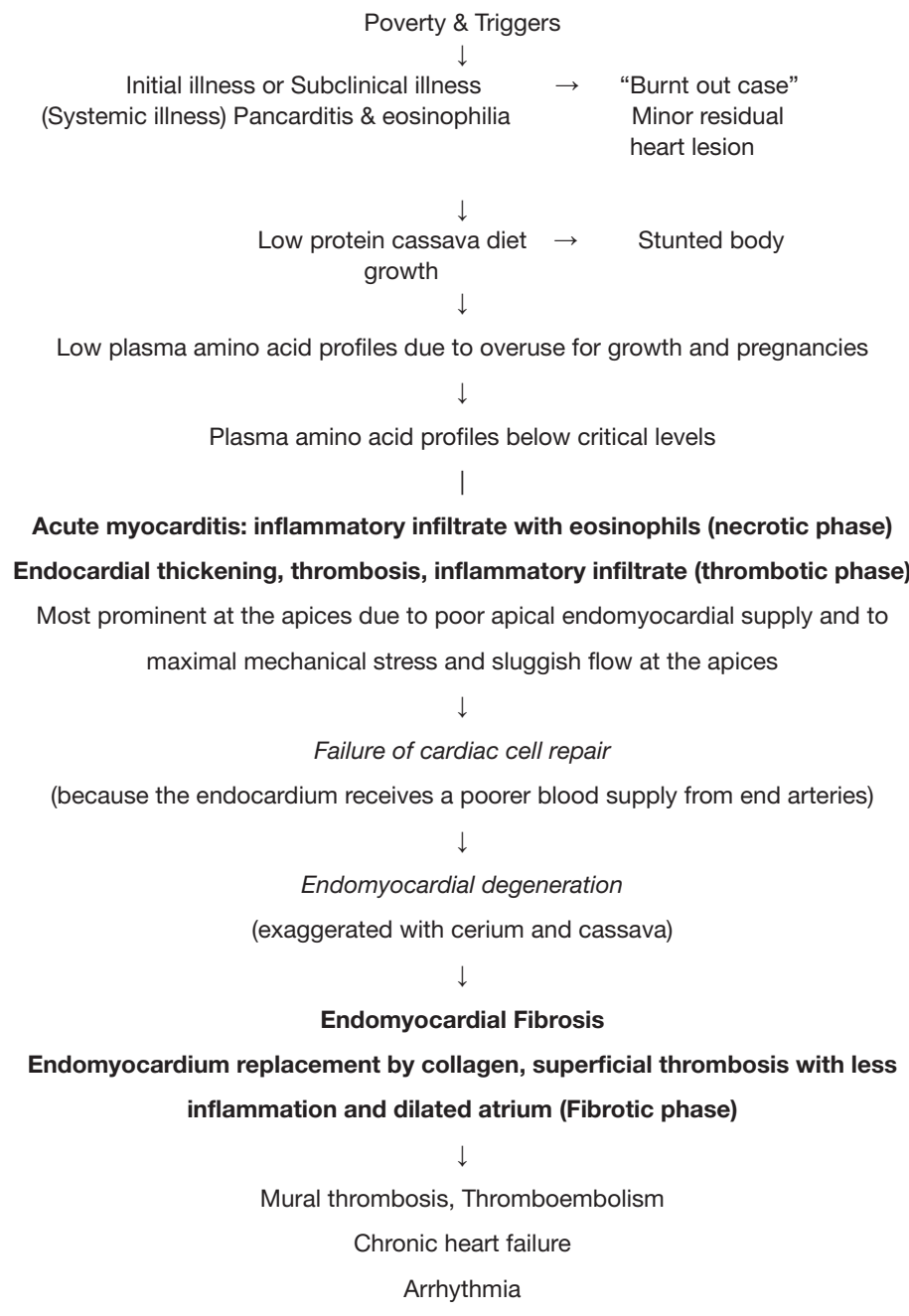

Figure 1 Diagram of EMF hypothetical pathogenesis, pathophysiology and natural history (adapted from Sezi 1996, Olsen 1990 and Parry 1965) (13-15).

Table 1 Endomyocardial fibrosis studies found on PubMed in the last 5 years indicating type of study and number of patients included

\begin{tabular}{|c|c|c|c|c|}
\hline Author, year of publication (ref) & Type of study & Number of patients & Country & Subject \\
\hline Sayegh, 2017 (22) & Prospective & 26 (15 healthy controls) & Brazil & Cardiopulmonary exercise testing \\
\hline Khalil, 2017 (23) & Case series & 23 & Sudan & $\begin{array}{l}\text { Echocardiographic and laboratory } \\
\text { findings }\end{array}$ \\
\hline Beaton, 2014 (26) & Descriptive & 71 (137 controls) & $\begin{array}{l}\text { Uganda, } \\
\text { Mozambique }\end{array}$ & Genetics-HLA \\
\hline Bossa, 2014 (27) & Descriptive & 27 (38 controls) & Brazil & Cytokines, inflammation \\
\hline
\end{tabular}


Table 2 Original research from Africa indicating the burden of EMF in patients submitted to echocardiography in hospital series in the last 5 years

\begin{tabular}{|c|c|c|c|}
\hline Author, publication date (ref) & Population characteristics & Frequency & Country (study duration) \\
\hline Yangni-Angate, 2016 (31) & Surgery for cardiac disease (mean age 12) & $126 / 2,612(4.8 \%)$ & Cote d'Ivoire (25 years) \\
\hline Nkoke et al. 2015 (33) & $\begin{array}{l}\text { Echocardiographic exams performed for children } \\
0-8 \text { years old with acquired heart disease }\end{array}$ & $22 / 156(13.9 \%)$ & Cameroon (5 months) \\
\hline Sani 2015 (34) & $\begin{array}{l}\text { Acquired heart disease patients in a prospective study } \\
\text { conducted }\end{array}$ & $7 / 110(6.4 \%)$ & Nigeria (60 months) \\
\hline
\end{tabular}

same country EMF corresponded to $13.9 \%$ of the 156 echocardiographic exams performed for acquired heart disease in children [0-18] (33). EMF was the diagnosis in 7 (6.4\%) of 110 children diagnosed with AHD in a prospective study conducted in a teaching hospital in Nigeria from 1st July 2009 to 30th June 2014 (34). Again, from Nigeria, a study of 116 children (mean age 6.7 years) referred for echocardiographic evaluation who had confirmed AHD in three centers in Nigeria over 42 months found 3 EMF cases $(2.3 \%)$ (35). These studies had different designs but it is interesting to see that the occurrence of EMF varied from $0.5 \%$ in series that included adults to $13.9 \%$ when the denominator was children with acquired heart disease (Table 2).

\section{Study area}

Community-based studies to assess the prevalence of EMF were implemented in Inharrime District, in the southern province of Inhambane, in Mozambique in the 2000s. Located in southern coastal Mozambique, the district of Inharrime is bordered by the Indian ocean, encompassing an area of $2,744 \mathrm{~km}^{2}$ and according to estimates projections from 2007, the district would have 122,907 inhabitants in 2014 (36). Fishing and familiar agriculture are the most important activities that the local people relaying to their subsistence with a very low income (37). The central village that hosts the administration is located $400 \mathrm{~km}$ from the first referral hospital with cardiologist. Less than $1 \%$ of households have access to electricity and potable water; there is a small number of health facilities and this reduced access to health services (36). The population density varies from high in the main village (Vila Sede) to extremely low in Nhapadiane (where many families have their nearest neighbour as far as 0.5 to $1 \mathrm{~km}$ from their house).

\section{Methods}

In order to document the geographical distribution of this disease in Southern Mozambique, a review of the medical records of patients treated at Maputo Central Hospital between 1987 and 1999 was performed (10). In this initial hospital-based study analysis was restricted to cases originating from the 3 provinces of Southern Mozambique. Cumulative incidences were computed for the period of 1987-1999, by age group, sex and residential district at disease onset. The geographical distribution of the disease in the 34 districts (administrative subdivisions) of the study area was then mapped.

In subsequent pilot community-based research led by B. Ferreira, we used cardiac auscultation for screening and echocardiography for confirmation of EMF cases (unpublished data). Recognizing that EMF may be asymptomatic and severe patients would not be able to reach the health facilities where echocardiography was being performed, we then deployed a large community-based study using echocardiographic screening in randomly selected households, to capture the highest possible number of 
participants. Sample selection was done by clustering at two levels: povoados and households. We selected 33 out of the 59 villages by simple random sampling. Community leaders from the selected villages created a list of all households in each povoado, from where the first household was selected by random sampling. Second stage clustering was done after arrival to the index household. Upon arrival informed consent was obtained, identification cards were issued to the family, and each member was assigned a unique identification number. The exact location of the house was captured using a GPS system to enable future follow up. Households surrounding the index family within the limits of the village were noted, a number attributed to each and simple random selection of the next household to be visited done. This procedure was repeated for the following families until we reached a minimum of cluster size of 30 subject.

Recruitment was conducted in 2007 and collected data on socio-demographic characteristic of the household (age, gender, race, household composition) and cardiovascular health (physical examination and echocardiography). A thorough list of household geographic location and its head's names was prepared with the help of community leaders, to facilitate randomization. A cardiologist, who was the Principal Investigator, led the research team (17).

\section{Main findings}

Although not undertaken in the community the first study analysed the geographic origin of EMF patients at the main referral hospital in Mozambique over a 10-year period, showing a striking high attack rate in the district of Inharrime (10), which had almost 7 times more EMF cases, when compared to other referring districts, including many that were closer to this cardiology unit.

The screening followed by echocardiography study found that $8 \%$ of people screened had EMF, confirming this disease as a major form of heart disease in that region (unpublished data); these figures were thought to be an underestimation of the real size of the problem, since cardiac auscultation can be normal in a considerable number of EMF patients with severe echocardiographic abnormalities $(38,39)$, particularly right forms with free tricuspid regurgitation.

Finally, the prevalence of EMF using exclusively echocardiographic screening in all ages was $19.8 \%$, showing that this technique adds sensitivity and precision to the diagnosis, by detecting early disease and asymptomatic individuals. A non-uniform distribution of the prevalence was found in the district with 12 out of the 33 selected counties reaching prevalence of more than $25 \%$, while others had less than $5 \%$ of people affected. The areas with higher prevalence of EMF were located mainly near lakes or rivers, but weather this is of relevance in search for an environmental factor as the trigger of EMF is an issue that needs to be further studied (17). Out of 214 families, 99 had no EMF cases, 63 had one case and 52 had more than one case. No correlation was found between the percentage of subjects with EMF in a family and the observed family size (correlation $=0.095 ; \mathrm{P}=0.17$ ), but the chance of having the disease was higher when other members of the family had it $(\mathrm{P}=0.001$, using a logistic regression model). If EMF status was independent of other members of the family, the prevalence among families with at least one case would be approximately $28 \%$. The observed prevalence was approximately $32 \%$ when another member of the family had the disease and reached $39 \%$ for subjects with three or more family members having the condition (17).

Some limitations to this study need to be highlighted. Firstly, echocardiographic findings suggesting EMF but not reaching the necessary scores to be considered definite cases may represent either early stages of the disease or are forms of mild disease persisting in quiescent stage forever. Secondly, 186 (14.9\%) eligible individuals were absent and therefore were not submitted to echocardiographic screening, but the results of the analysis of the demographic characteristics of these individuals did not differ from those found in the whole sample of the population. The mean age of the absent was 22.6 years $(\mathrm{Se}=0.5)$, and 99 were adult male who worked in neighbouring South Africa. Thirdly, if genetic factors are involved the high prevalence of EMF in the Mozambique study (17) may be related to our sampling methodology of familial clustering and counting all individuals in a family, in which case it might be informative to recalculate prevalence based on only an index case per family.

Currently, efforts to follow up patients detected in the community are undergoing in this endemic area to understand the natural history and outcomes of EMF in this community, but re-evaluations at planned time points have been delayed by civil war incidents in 2016/2017 (40).

\section{Lessons learned}

These studies highlighted the need for further research into the mode, mechanisms and rate of progression of EMF, as well as the role of genetic susceptibility in determining its 
different phenotypes and familial occurrence. Our program also unveils the challenges of implementing longitudinal community-based research in low-income countries such as Mozambique.

The main barriers encountered were mostly related to poor implantation of administrative authorities and infrastructure in the most remote areas, but also to poverty and lack of adequate environment to perform certain measurements within the households. Corroborating data from the national censuses showing low number of public infrastructures—especially secondary schools (36) considerable number of children did not attend school due to the long distances from home; early withdrawal was common, particularly for girls. The mapping of the setting shows sparse administrative, education and health infrastructures, thus resulting in reduced access to health care and administrative services for those in remote areas.

While researchers were aware of mobility issues during the rainfall season-related to poor road infrastructurelow distribution of the power network, existence of blind spots on the telecommunication network, and frequent change of phone numbers by the participants where the biggest hurdles when trying to coordinate fieldwork, making it impossible to timely contact participants or community leaders from remote zones. As people practice subsistence agriculture (slash and burn agriculture), and often shift from one place to another looking to more fertile soils (41), lack of reliable ways of communication becomes a major barrier to the success of fieldwork.

Another major barrier was the fact that given names in this community are often changed at time of schooling, while traditional names are continuously used inside the family circle. Quite often only the father or elder siblings know the "official given name". In addition, like in other parts of the country, only few children are officially registered and have a national identification number prior to entering school. Moreover, with a low proportion of children born in hospital in these remote areas (42), not all have their birth dates correctly registered or hold health cards with their names.

Emigration is another serious challenge, particularly for follow-up studies. In our prevalence study in Inharrime District 186 (14.9\%) eligible individuals were absent at the time of the study and therefore could not be observed; their mean age was 22.6 years $(\mathrm{Se}=0.5)$ and the proportion varied between $9.6 \%$ and $22.4 \%$ in different villages (17). Half of the absent (99 out of 186) were adult male who lived and worked in the neighbouring country of South Africa.

Finally, language can also be a major barrier, as more than 50 languages are spoken in Mozambique (43). In this endemic area for EMF only a small proportion of participants were fluent in Portuguese, the official language in Mozambique. Thus, research teams would always include trained members of the community acting as guides, translating the questionnaires, as well as liaising with the community-leaders and participants.

The constraints we discussed represent a threat to the scientific quality of data acquisition, systematization and information/feedback sharing $(3,4,44)$ and need to be considered when planning longitudinal studies in rural settings in Africa. Strategies to overcome these challenges include an extensive initial profiling of the setting and multiple preparatory contacts with local stakeholders, which may be very expensive and time-consuming. In our experience, baseline data should include as much information as possible and include obtaining multiple modes of contact, pictures of the setting - and eventually of the participants-to serve as a recall aid years later. We strongly believe that these measures are key to success, while lack of vital statistics, transport network, reliable telecommunications, and widespread services of education and health are available in these rural communities.

\section{Perspectives}

\section{Diagnosis \& management}

While local cardiologists easily make the diagnosis of $\mathrm{EMF}$, they are few and thus there is need to increase physicians, health personnel, population and health authority's awareness of the disease. The provision of standard diagnostic criteria and clear nomenclature for the different stages of the disease, would allow standardization of classification and progress in management. Due to complexity of the mechanisms involved and lack of understanding of the pathways to heart failure, there is probably need to incorporate pre-clinical features, biomarkers and modern imaging modalities to the classification. Moreover, an international expert committee might be needed to support writing up a standard international classification for diagnosing the condition, and supporting the management of its various stages and forms. 


\section{Biomarkers}

The definition of the biological profile of EMF patients is of paramount importance, particularly clarifying the role of the eosinophil. Eosinophil cationic protein released from activated eosinophils are known to increase the release of TGF- $\beta 1$ from fibroblasts, potentially the mechanism by which they cooperate in remodelling of the extra cellular matrix leading to airway fibrosis in asthmatic patients (45). Eotaxins-the most potent chemoattractant for eosinophils, inducing their local recruitment from the microcirculation as well as rapid mobilization of bone marrow eosinophils, in synergy with IL5 $(46,47)$ - have been shown to be produced in cardiac tissue from EMF patients, namely by smooth-muscle cells, endothelial cells, alveolar macrophages, lymphocytes, eosinophils. Relating this research to EMF mechanisms may provide knowledge to identify new therapeutic targets and potentially alter the natural history of EMF, considering that drugs to control hypereosinophilia, high levels of IL-5 and eotaxins are currently available (48-50). Biomarkers such as BNP can potentially be relevant to early diagnosis of paucisymptomatic EMF but are still unaffordable in endemic regions.

\section{Imaging}

Echocardiography is the most readily available technique for EMF diagnosis and seems to correlate well with findings in surgery (51) and post-mortem, but magnetic resonance imaging (MRI) is particularly useful in patients with distorted anatomy and for monitoring response to medical and surgical treatment (52). MRI is an expensive technique and thus unavailable in most endemic areas for EMF (53). When available it may be used to confirm presence of thrombus or calcification, delineate hypoperfused areas corresponding to fibrosis, assess their extension using delayed hyperenhancement and provide hemodynamic information $(53,54)$.

\section{Management}

Systematic evaluation of the outcomes of therapies used in EMF is lacking. A clinical trial that recruited 35 EMF patients with large ascitis randomized to receive $1 \mathrm{mg} / \mathrm{kg}$ per day of prednisolone or placebo and followed for up to 8 weeks showed that short-term prednisolone use is safe but does not prevent re-accumulation of ascites (25). Regarding surgery-initially based on extensive endocardial resection associated with atrioventricular valve prosthesisthe technique has evolved and currently addresses the different disease components; reparative operations target fibrous plaques interfering with regional ventricular function, reduced ventricular volume due to ventricular obliteration, immobilization of the papillary muscles from atrioventricular valves, chordal abnormalities, fusion of the leaflets to the wall, dilatation of the tricuspid and mitral annulus, and massive atrial dilatation (55). Additionally, procedures of cavopulmonary shunting have been added to deal with right ventricle obliteration or retraction. Progress in surgical techniques has been supported by developments in imaging techniques such as tissue Doppler imaging (56), tridimensional echocardiography (57), computed tomography (58) and MRI (24).

\section{Research}

After initial work looking at different etiological hypothesis for EMF, most publications on this condition have been case reports or descriptive studies in hospital setting. Recognition of the need for partnerships to developed research capacity in African institutions has led to collaborative work between researchers in affected regions and their partners from developed world. In the 2000s in Mozambique research using portable cardiac ultrasound assessed EMF prevalence in the general population, defined diagnostic criteria to improve disease profiling and proposed new surgical techniques for disease management. More recently, Uganda - the country that pioneered EMF-related research in the $40 \mathrm{~s}$ (59) — and Mozambique, two countries with low health budgets (60) and high prevalence of povertyrelated chronic cardiovascular diseases (61) have partnered for community-based research in Mozambique (62) (Figure 2). As an example of this regional effort, genetic susceptibility is being explored in a Pan-African multicenter prospective cohort study (the IMHOTEP registry) aiming to phenotype and classify adults and children with cardiomyopathy, perform genetic association studies for susceptibility genes, and determine the outcome of cardiomyopathy in Africans.

Because the knowledge gap is huge for EMF, its reported decline in some geographic areas must not lead to retraction in interest from researchers and funding bodies, particularly as new knowledge in endothelial cell biology, inflammation, hemostasis, regulation of collagen synthesis, remodelling and mechanisms of fibrosis may allow earlier detection and uncover new therapeutic targets for this highly debilitating condition. 


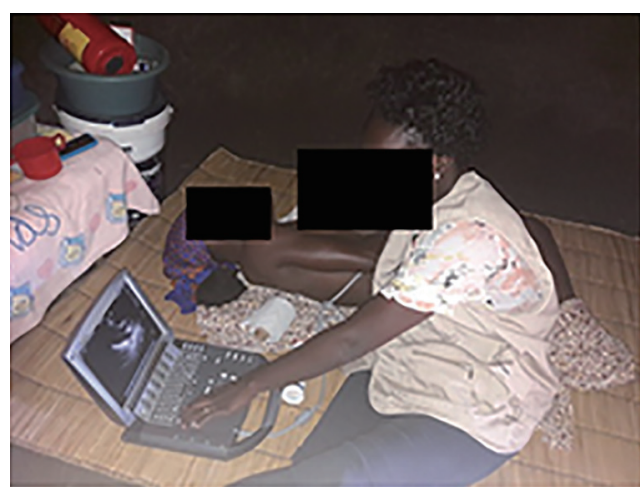

Figure 2 Image of researcher performing cardiac ultrasound in a remote area of Mozambique, inside a participant's house as part of follow up studies on EMF. EMF, endomyocardial fibrosis.

\section{Acknowledgments}

Funding: None.

\section{Footnote}

Provenance and Peer Review: This article was commissioned by the Guest Editor (Ntobeko A. B. Ntusi) for the series "Cardiovascular Diseases in Low-and Middle-Income Countries" published in Cardiovascular Diagnosis and Therapy. The article was sent for external peer review organized by the Guest Editor and the editorial office.

Conflicts of Interest: The series "Cardio-vascular Diseases in Low- and Middle-Income Countries" was commissioned by the editorial office without any funding or sponsorship. The authors have no conflicts of interest to declare.

Ethical Statement: The authors are accountable for all aspects of the work in ensuring that questions related to the accuracy or integrity of any part of the work are appropriately investigated and resolved.

Open Access Statement: This is an Open Access article distributed in accordance with the Creative Commons Attribution-NonCommercial-NoDerivs 4.0 International License (CC BY-NC-ND 4.0), which permits the noncommercial replication and distribution of the article with the strict proviso that no changes or edits are made and the original work is properly cited (including links to both the formal publication through the relevant DOI and the license). See: https://creativecommons.org/licenses/by-nc-nd/4.0/.

\section{References}

1. Elmawazini K, Manga P, Nwankwo S, et al. Health gap between developed and developing countries: Does globalization matter? Econ Change Restruct 2019;52:123-38.

2. Chhanabhai PN, Holt A. The Disparity Information and Communication Technology Developing Countries has in the Delivery of Healthcare Information. Open Med Inform J 2010;4:195-201.

3. Casale M, Lane T, Sello L, et al. Conducting health survey research in a deep rural South African community: challenges and adaptive strategies. Health Res Policy Syst 2013;11:14.

4. Holden RJ, McDougald Scott A, Hoonakke P, et al. Data collection challenges in community settings: Insights from two field studies of patients with chronic disease. Qual Life Res 2015;24:1043-55.

5. Odekunle FF, Odekunle RO, Shankar S. Why subSaharan Africa lags in electronic health record adoption and possible strategies to increase its adoption in this region. Int J Health Sci (Qassim) 2017;11:59-64.

6. Mocumbi A, Prista A, Kintu A, et al. Doenças Crónicas e Não Transmissíveis em Moçambique: Uma iniciativa de equidade no controle de Doenças Não Transmissiveis e Trauma-Relatório Nacional. Maputo; 2018.

7. Mahdi S, Massingue ACA, Massarongo C, Fernanda AP, Baez R, Javier E, et al. Mozambique Economic Update : Shifting to More Inclusive Growth [Internet]. Vol. 136, Journal of Experimental Psychology: General. Washington, D.C. : World Bank Group.; 2018. Available online: http://documents.worldbank.org/curated/ en/132691540307793162/Mozambique-EconomicUpdate-Shifting-to-More-Inclusive-Growth

8. Schwitters A, Lederer P, Zilversmit L, et al. Barriers to health care in rural Mozambique: a rapid ethnographic assessment of planned mobile health clinics for ART. Glob Health Sci Pract 2015;3:109-16.

9. World Health Organization. Health in 2015: from MDGs, Millennium Development Goals to SDGs, Sustainable Development Goals. 2015. Available online: http://apps.who.int/medicinedocs/en/m/abstract/ Js22230en/

10. Ferreira B, Matsika-Claquin M, Mocumbi A, et al. Geographic origin of endomyocardial fibrosis treated at the central hospital of Maputo (Mozambique) between 1987 and 1999. Bull Soc Pathol Exot 2002;95:276-9.

11. Lachaud M, Lachaud C, Sidi D, et al. Fibrose 
endomyocardique tropicale: perspectives. Annales de cardiologie et d'angeiologie 2018;67:74-81.

12. Grimaldi A, Mocumbi AO, Freers J, et al. Tropical Endomyocardial Fibrosis Natural History, Challenges, and Perspectives Antonio. Circulation 2016;133:2503-15.

13. Sezi CL. Effect of protein deficient cassava diet on Cercopithecus aethiops hearts and its possible role in the aetiology and pathogenesis of endomyocardial fibrosis in man. East Afr Med J 1996;73:S11-6.

14. Olsen E. Morphological overview and pathogenic mechanism in EMF associated with eosinophilia. In: Olsen EGJ, Sekiguchi M (eds). Cardiomyopathy update 3. 1990;21.

15. Parry EH, Abrahams DG. The natural history of endomyocardial fibrosis. Q J Med 1965;34:383-408.

16. Beck W, Schrire V. Endomyocardial fibrosis in Caucasians previously resident in tropical Africa. Br Heart J 1972;34:915-8.

17. Mocumbi AO, Ferreira M, Sidi D, et al. A Population Study of Endomyocardial Fibrosis in a Rural Area of Mozambique. New Engl J Med 2008;359:43-9.

18. Patel AK, Ziegler JL, D'Arbela PG, et al. Familial Cases of Endomyocardial Fibrosis in Uganda. Br Med J 1971;4:331-4.

19. Lowenthal MN. Endomyocardial fibrosis: familial and other cases from northern Zambia. Med J Zambia 1978;12:2-7.

20. Davies J. Endomyocardial fibrosis in Africans. East Afr Med J 1948;25:10-7.

21. Gupta PN, Kunju SM, Rajan B, et al. Geographical variation in the clinical presentation of endomyocardial fibrosis in India? Indian Heart J 2018;70:56-65.

22. Sayegh ALC, Santos MRD, Oliveira P, et al. Characterization of Cardiopulmonary Exercise Testing Variables in Patients with Endomyocardial Fibrosis after Endocardial Resection. Arq Bras Cardiol 2017;109:53340.

23. Khalil SI, Khalil S, Tigani S, et al. Cardiovascular Topics Endomyocardial fibrosis in Sudan: clinical and echocardiographic features. Cardiovasc J Afr 2017;28:208-14.

24. Leena R. Retrospective analysis of MR imaging characteristics and demographic characteristics of Tropical Endomyocardial fibrosis in a tertiary care centre in South India. J Cardiovasc Magn Reson 2016;18:1-3.

25. Nabunnya Y, Kayima J, Longenecker C, et al. The safety and efficacy of prednisolone in preventing reaccumulation of ascites among endomyocardial fibrosis patients in
Uganda: a randomized clinical trial. BMC Res Notes 2015;8:783.

26. Beaton A, Sable S, Brown J, et al. Genetic susceptibility to endomyocardial fibrosis. Glob Cardiol Sci Pract. 2014;2014:473-81.

27. Bossa A, Salemi V, Ribeiro S, et al. Plasma Cytokine Profile in Tropical Endomyocardial Fibrosis:

Predominance of TNF- a, IL-4 and IL-10. PLoS One 2014;9:e108984.

28. Vijayaraghavan G, Sivasankaran S. Tropical endomyocardial fibrosis in India: a vanishing disease! Indian J Med Res 2012;136:729-38.

29. Mocumbi AO. Recent trends in the epidemiology of endomyocardial fibrosis in Africa. Paediatr Int Child Health 2012;32:63-4.

30. Rwebembera J, Manyilirah W, Zhu Z, et al. Prevalence and characteristics of primary left-sided valve disease in a cohort of 15, 000 patients undergoing echocardiography studies in a tertiary hospital in Uganda. BMC Cardiovasc Disord 2018;18:82.

31. Yangni-Angate KH, Meneas C, Diby F, et al. Cardiac surgery in Africa: a thirty-five year experience on open heart surgery in Cote d' Ivoire. Cardiovasc Diagn Ther 2016;6:S44-63.

32. Chelo D, Nguefack F, Menanga AP, et al. Fibrose endomyocardique: description clinique et échocardiographique d'une série pédiatrique camerounaise. Archives de Pédiatrie 2016;23:128-35.

33. Nkoke C, Menanga A, Boombhi J, et al. A new look at acquired heart diseases in a contemporary sub- Saharan African pediatric population: the case of Yaoundé, Cameroon. Cardiovasc Diagn Ther 2015;5:428-34.

34. Sani UM, Ahmed H, Jiya NM. Pattern of acquired heart diseases among children seen in Sokoto, North-Western Nigeria. Niger J Clin Pract 2015;18:718-25.

35. Wilson SE, Chinyere UC, Queennette D. Childhood acquired heart disease in Nigeria: an echocardiographic study from three centres. Afr Health Sci 2014;14:609-16.

36. INE. Estatísticas do Distrito de Inharrime [Internet]. INE. Maputo; 2013. p. 32. Available online: http://www. ine.gov.mz/estatisticas/estatisticas-territorias-distritais/ inhambane/novembro-de-2013/inharrime.pdf/view accessed 11 August 2019

37. MAE. Perfil do Distrito the Inharrime [Internet]. Maputo; 2005. Available online: http://inharrime. inhambane.gov.mz/informacao/Perfil_Inharrime.pdf accessed 11 August 2019

38. Chimenti C, Pieroni M, Frustaci A. Endomyocardial 
fibrosis mimicking a dilated cardiomyopathy in a child. Heart 2001;86:73.

39. Salemi VM, Rochitte CE, Barbosa MM, et al. Images in cardiology. Clinical and echocardiographic dissociation in a patient with right ventricular endomyocardial fibrosis. Heart 2005;91:1399.

40. Forquilha S. Descentralização e Conflito em Moçambique: o desafio da construção do estado. IESE. 2017. p. 35-59. Available online: http://www.iese.ac.mz/ wp-content/uploads/2018/05/part1-2sf.pdf accessed 11 August 2019

41. Dewees PA, Campbell BM, Katerere Y, et al. Managing the miombo woodlands of Southern Africa: Policies, incentives and options for the rural poor. J Nat Resour Policy Res 2010;2:57-73.

42. Kinney MV, Kerber KJ, Black RE, et al. Sub-Saharan Africa's mothers, newborns, and children: where and why do they die? PLoS Med 2010;7:e1000294.

43. UNICEF. The impact of language policy and practice on children's learning: Evidence from Eastern and Southern Africa. 2016. Available online: https://www. unicef.org/esaro/UNICEF(2016)LanguageandLearningFullReport(SingleView).pdf

44. Abimanyi-Ochom J. Practicalities of health survey fieldwork research in a resource limited setting: challenges and lessons learnt from Uganda. Afr Health Sci 2017;17:278-84.

45. Zagai U, Dadfar E, Lundahl J, et al. Eosinophil Cationic Protein Stimulates TGF- b 1 Release by Human Lung Fibroblasts In Vitro. Inflammation 2007;30:153-60.

46. Collins PD, Marleau S, Griffiths-Johnson DA, et al. Cooperation between Interleukin-5 and the Chemokine Eotaxin to Induce Eosinophil Accumulation In Vivo. J Exp Med 1995;182:1169-74.

47. Palframan RT, Collins PD, Williams TJ, et al. Eotaxin induces a rapid release of eosinophils and their progenitors from the bone marrow. Blood 1998;91:2240-8.

48. Rothenberg ME, Klion AD, Roufosse FE, et al. Treatment of Patients with the Hypereosinophilic Syndrome with Mepolizumab. N Engl J Med 2008;358:1215-28.

49. Sutton SA, Assa'ad AH, Rothenberg ME. Anti-IL-5 and hypereosinophilic syndromes. Clin Immunol 2005;115:51-60.

50. Morokata T, Suzuki K, Masunaga Y, et al. A Novel, Selective, and Orally Available Antagonist for CC Chemokine Receptor 3. J Pharmacol Exp Ther
2006;317:244-50.

51. Mocumbi AO, Carrilho C, Sarathchandra P, et al. Echocardiography accurately assesses the pathological abnormalities of chronic endomyocardial fibrosis. Int J Cardiovasc Imaging. 2011;27:955-64.

52. Smedema JP, Winckels SKG, Snoep G, et al. Tropical endomyocardial fibrosis (Davies' disease): case report demonstrating the role of magnetic resonance imaging. Int J Cardiovasc Imaging 2004;20:517-22.

53. Cury RC, Abbara S, Sandoval LJD, et al. Images in Cardiovascular Medicine Visualization of Endomyocardial Fibrosis by Delayed-Enhancement Magnetic Resonance Imaging. Circulation 2005;111:e115-7.

54. Estornell J, López MP, Dicenta F, et al. Usefulness of Magnetic Resonance Imaging in the Assessment of Endomyocardial Disease. Rev Esp Cardiol 2003;56:321-4.

55. Mocumbi AO, Sidi D, Vouhe P, et al. An innovative technique for the relief of right ventricular trabecular cavity obliteration in endomyocardial fibrosis. J Thorac Cardiovasc Surg 2007;134:1070-2.

56. Black D, Vettukattil J. Advanced Echocardiographic Imaging of the Congenitally Malformed Heart. Curr Cardiol Rev 2013;9:241-52.

57. Hahn R. Recent advances in echocardiography for valvular heart disease. F1000Res 2015;4:914.

58. Atzeni F. Cardiovascular imaging Techniques in Systemic Rheumatic Diseases. Front Med (Lausanne) 2018;5:26.

59. Davies JNP, Ball JD. The pathology of endomyocardial fibrosis in Uganda. Br Heart J 1955;17:337-59.

60. UNICEF. Health Budget Brief. 2017. Available online: https://www.unicef.org/esaro/UNICEF_ Mozambique_--_2017_--_Health_Budget_Brief.pdf

61. WHO. Noncommunicable diseases country profiles 2018. Switzerland; 2018. Available online: https://www. who.int/nmh/publications/ncd-profiles-2018/en/

62. Namuyonga J, Lwabi PS, Omagino J, et al. Feasibility of south-south collaboration in Africa: the UgandaMozambique perspective. Cardiovasc J Afr 2018;29:262-3.

Cite this article as: Mbanze J, Cumbane B, Jive R, Mocumbi A. Challenges in addressing the knowledge gap on endomyocardial fibrosis through community-based studies. Cardiovasc Diagn Ther 2020;10(2):279-288. doi: 10.21037/cdt.2019.08.07 